\title{
Smoking and alcohol, health-related quality of life and psychiatric comorbidities in Leber's Hereditary Optic Neuropathy mutation carriers: a prospective cohort study
}

\author{
Andrea Rabenstein ${ }^{1 * \dagger} \mathbb{D}$, Claudia B. Catarino ${ }^{2 \dagger}$, Verena Rampeltshammer ${ }^{1}$, David Schindler ${ }^{1}$, \\ Constanze Gallenmüller ${ }^{2}$, Claudia Priglinger ${ }^{3}$, Oliver Pogarell ${ }^{1}$, Tobias Rüther ${ }^{1 \dagger}$ and Thomas Klopstock $2,4,5^{*+}$
}

\begin{abstract}
Background: Leber's hereditary optic neuropathy (LHON) is a rare mitochondrial disorder, characterized by acute or subacute bilateral vision loss, frequently leading to significant chronic disability, mainly in young people. The causal LHON mutations of the mitochondrial DNA have incomplete penetrance, with the highest risk of disease manifestation for male mutation carriers in the second and third decades of life. Here we evaluated smoking, alcohol drinking habits, health-related quality of life (QOL) and psychiatric comorbidities in a cohort of LHON patients and asymptomatic mutation carriers from a tertiary referral centre.
\end{abstract}

Methods: Cross-sectional analysis of the ongoing Munich LHON prospective cohort study. Participants included all LHON patients and asymptomatic LHON mutation carriers older than 16 years at baseline, who were recruited between February 2014 and June 2015 and consented to participate. General, neurological and ophthalmological investigations were performed, including validated questionnaires on smoking, alcohol drinking habits, depressive symptoms and health-related QOL.

Results: Seventy-one participants were included, 34 LHON patients (82\% male) and 37 asymptomatic mutation carriers (19\% male). Median age at baseline was 36 years (range 18-75 years). For LHON patients, median age at visual loss onset was 27 years (9 to 72 years). Smoking is more frequent in LHON patients than asymptomatic LHON mutation carriers, and significantly more frequent in both groups than in the general population. Sixty percent of LHON patients, who smoked at disease onset, stopped or significantly reduced smoking after visual loss onset, yet $40 \%$ of LHON patients continued to smoke at study baseline. Excessive alcohol consumption is more frequent in male LHON

\footnotetext{
*Correspondence: andrea.rabenstein@med.uni-muenchen.de; tklopsto@med.LMU.de

${ }^{\dagger}$ Andrea Rabenstein and Claudia B. Catarino contributed equally to the manuscript

†Tobias Rüther and Thomas Klopstock jointly supervised this work/ contributed equally to the manuscript

${ }^{1}$ Department of Psychiatry and Psychotherapy, Ludwig-Maximilians University München, Nussbaumstr. 7, 80336 Munich, Germany

${ }^{2}$ Department of Neurology, Friedrich-Baur Institute, Ludwig-Maximilians University München, Ziemssenstr. 1a, 80336 Munich, Germany

Full list of author information is available at the end of the article
}

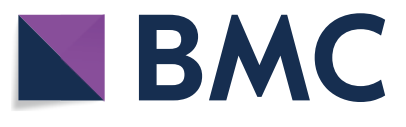

(c) The Author(s) 2021. Open Access This article is licensed under a Creative Commons Attribution 4.0 International License, which permits use, sharing, adaptation, distribution and reproduction in any medium or format, as long as you give appropriate credit to the original author(s) and the source, provide a link to the Creative Commons licence, and indicate if changes were made. The images or other third party material in this article are included in the article's Creative Commons licence, unless indicated otherwise in a credit line to the material. If material is not included in the article's Creative Commons licence and your intended use is not permitted by statutory regulation or exceeds the permitted use, you will need to obtain permission directly from the copyright holder. To view a copy of this licence, visit http://creativecommons.org/licenses/by/4.0/. The Creative Commons Public Domain Dedication waiver (http://creativeco mmons.org/publicdomain/zero/1.0/) applies to the data made available in this article, unless otherwise stated in a credit line to the data. 
patients than in LHON asymptomatic and more frequent than in the male general population. Further, female asymptomatic LHON mutation carriers are at risk for depression and worse mental QOL scores.

Conclusions: Given the high prevalence of smoking and excessive drinking in LHON mutation carriers, implementing effective measures to reduce these risk factors may have a significant impact in reducing LHON disease conversion risk. The underrecognized prevalence of mental health issues in this population of LHON mutation carriers highlights the need for awareness and more timely diagnosis, which may lead to improved outcomes.

Keywords: Smoking, Alcohol, Mitochondrial disorder, Depression, Leber's hereditary optic atrophy, LHON, Quality of life, Mental health $(<10)$

\section{Background}

Leber's Hereditary Optic Neuropathy (LHON, OMIM \#535000) is one of the most frequent mitochondrial disorders, with an estimated prevalence of 1:31,000 [1]. LHON leads to subacute bilateral vision loss, progressing within weeks or months, often resulting in significant chronic visual disability. Spontaneous recovery may occur, yet long-term visual outcome is often poor. Onset of visual loss is most frequent in male adults in the second or third decades of life [2], although female patients, childhood-onset cases [3, 4] and late-onset cases [5] may be underdiagnosed. More than $90 \%$ of LHON is caused by one of three frequent point mutations of the mitochondrial DNA (mtDNA), m.11778G $>$ A [6], m.3460G > A [7] or m.14484T >C [8], in genes coding subunits of complex I of the respiratory chain of the mitochondria [2]. Dysfunction of complex I leads to reduced adenosine triphosphate (ATP) production [9], increased reactive oxygen species, which cause dysfunction of the retinal ganglion cells (RGC), which are particularly susceptible to mitochondrial dysfunction, and later cause apoptosis of a proportion of the RGC [10]. LHON follows maternal inheritance with incomplete penetrance. There is a substantial differential risk between genders, as $50 \%$ of male but only $10 \%$ of female LHON mutation carriers may develop visual loss due to LHON in their lifetime [2]. This suggests a role for other genetic $[11,12]$ and environmental modifiers [13-15]. Environmental factors add to the genetic risk and some are modifiable, such as smoking and excessive alcohol consumption [11]. Epidemiological studies showed smoking is a risk factor for a mutation carrier to develop LHON symptoms [11]. An association between smoking and decreased complex I activity [16] suggests a mechanism for how smoking may aggravate genetically-determined mitochondrial dysfunction in LHON. Indeed, the risk of disease for male LHON mutation carriers was shown to increase from 50 to $93 \%$ in smokers in a large epidemiological study [11, 17]. Heavy alcohol intake has also been associated with a trend for increased risk of disease in LHON carriers [11]. Further, it has been shown that onset of visual loss negatively impact the quality of life of LHON mutation carriers [18]. A systematic analysis of health-related QOL and psychiatric comorbidities in a population of LHON patients and asymptomatic LHON mutation carriers has not yet been reported. With this study, we aimed to quantify the modifiable environmental risk factors, particularly smoking behaviour and alcohol consumption habits, as well as depressive symptoms and health-related QOL, for both LHON patients and asymptomatic LHON mutation carriers in a large well-characterized cohort.

\section{Methods}

\section{Participants; LHON patients and asymptomatic LHON mutation carriers}

Of 81 participants recruited from February 2014 to June 2015 in the Munich LHON cohort study, 71 were 16 years and older at baseline and were included in the final analysis. Thirty-four (48\%) were LHON patients with a known pathogenic LHON mutation of the mtDNA and 37 (52\%) were asymptomatic LHON mutation carriers. All participants and legal guardians (for participants under the age of 18) gave written informed consent or assent. The local Ethics committee of the Ludwig-Maximilians-University (LMU) of Munich approved this project (project number 278-13).

\section{Study design}

Participants in the Munich LHON cohort study are examined at baseline and thereafter annually by an expert team of neurologists, ophthalmologists and psychiatrists in the outpatient clinics of the LMU University Hospital. Each visit includes thorough medical history, family history, as well as systematic general, neurological and ophthalmological examinations, and laboratory examinations. Validated questionnaires on smoking habits and alcohol consumption, quality of life and psychiatric comorbidities are completed at each visit. All subjects are advised at each visit to quit smoking, moderate alcohol intake and keep a balanced diet. Information on smoking cessation programmes is provided to all participants, who smoke. 


\section{Smoking-related data}

The accuracy of self-reported smoking status was checked by determining the concentration of carbon monoxide in expired air, measured with a calibrated smoking meter BMC 2000 (SNEKO, Osan). Ninety-six percent of participants, who smoked at baseline, completed the Fagerström Test for Nicotine Dependence (FTND), which measures the degree of nicotine dependence $[19,20]$. Smoking was quantified in pack-years. A current smoker was defined if the participant smoked in the last 30 days; or ex-smoker, if they smoked more than 100 times but not in the last 30 days; and non-smoker, if they smoked in total less than 100 times in life [21]. The proportion of smokers, for both LHON patients and asymptomatic LHON mutation carriers, was compared to the prevalence in the general population in Germany, stratified by gender [22].

\section{Alcohol consumption data}

The Alcohol Use Disorders Identification Test (AUDIT) questionnaire for detection of excessive alcohol consumption [23], which includes an estimation of number of days with alcohol consumption in the previous 30 days, and type and number of alcoholic beverages in an average day of alcohol consumption, was completed by $93 \%(66 / 71)$ of the participants. Total amount and average daily alcohol consumption were calculated for each participant. The alcohol-by-volume (ABV) measures used were $4.8 \%$ for beer, $11.0 \%$ for wine/sparkling wine and $33.0 \%$ for liquor [24]. For both groups, a quantity-frequency-index was calculated as a measure of alcohol consumption. For all participants this was calculated at study baseline; and, for LHON patients, also for the six months preceding onset of visual loss. Excessive daily alcohol consumption was defined as more than $12 \mathrm{~g} /$ day for females, and $24 \mathrm{~g} /$ day for male participants [25]. Seventy-nine percent of LHON patients and $73 \%$ of asymptomatic LHON mutation carriers answered the question on estimated daily amount of alcohol consumption at study baseline.

\section{Data collection on depressive symptoms}

The Beck Depression Inventory (BDI-I) is a 21 -item selfreport measure of depressive symptoms [26], which was completed by $88 \%(30 / 34)$ of LHON patients and $89 \%$ (33/37) of asymptomatic LHON mutation carriers. Cutoff values were used as recommended by the current German S3/ National health policy guidelines on depression [27]. The frequency of depression in both LHON patients and in LHON asymptomatic mutation carriers was compared with the prevalence rate of depression in the general population, which currently is $16-20 \%[28,29]$, with the frequency of depressive symptoms estimated at $10.2 \%$ for females and $6.1 \%$ for males in the German population [30].

\section{Health-related quality of life (QOL)}

Health-related QOL was assessed using the SF-12 version 2 (SF-12 v2) questionnaire [31]. Ninety-six percent (68/71) of participants completed the SF-12 v2 questionnaire. Two sub-scores were calculated, the Physical Component Summary (PCS) and the Mental Component Summary (MCS). Both sub-scores were compared with normative data for the general population, stratified by gender [32].

\section{Statistical analysis}

Nominal data were compared by Chi-square tests and Fisher's exact tests. Continuous data were compared by independent sample t-tests and one sample t-tests. As gender distribution was significantly different between LHON patients and asymptomatic LHON mutation carriers in our study, the statistical analyses were stratified by gender. Statistical analyses were performed using SPSS version 25.0 for Windows (Armonk, NY:IBM Corp., 2018). A $p$ value of less than 0.05 was considered statistically significant.

\section{Results}

The demographic characteristics of the 71 study participants are summarized in Table 1.

Of 34 LHON patients, 28 (82\%) were male (male:female ratio $4.7: 1$ ). Median age at study baseline was 36 years (range 18-75 years). Median age at clinical onset was 27 years (range 9-72 years). Median duration of disease at study baseline was 2.5 years (range 4 months -37 years). Twenty-five LHON patients (74\%) were treated with idebenone $900 \mathrm{mg} /$ day.

Of 37 asymptomatic LHON mutation carriers, seven (19\%) were male (male:female ratio 1:4.3), with median age at baseline 43 years (range 18-70 years). The gender distribution was significantly different between LHON patients and asymptomatic mutation carriers. Most asymptomatic LHON mutation carriers (94\%) are related to LHON patients also included in the study.

Sixty-eight participants (96\%) had one of the three primary LHON mutations of the mtDNA, and only three had a rare causal LHON mutation, one patient had the mutation m.14487 T>C [33] in the ND6 gene $(n=1)$ while one patient and one asymptomatic mutation carrier had the mutation m.3958G > A [34] in the ND1 gene. Vitamin B12 deficiency was measured at baseline or documented in the previous medical history in $44 \%$ of the LHON patients in our cohort. 
Table 1 Demographic characteristics and type of mutation of the participants in the present study

\begin{tabular}{|c|c|c|c|}
\hline & LHON patients $(n=34)$ & $\begin{array}{l}\text { Asymptomatic LHON mutation carriers } \\
(\mathrm{n}=37)\end{array}$ & Total $(n=71)$ \\
\hline \multicolumn{4}{|l|}{ Gender, $n(\%)$} \\
\hline M & $28(82 \%)$ & $7(19 \%)$ & 35 (49\%) \\
\hline$F$ & $6(18 \%)^{*}$ & $30(81 \%)^{*}$ & $36(51 \%)$ \\
\hline M:F ratio & $4.7: 1$ & $1: 4.3$ & N/A \\
\hline \multicolumn{4}{|c|}{ Age at study baseline (y) } \\
\hline Mean $( \pm S D)$ & $38( \pm 14)$ & $42( \pm 13)$ & $40( \pm 14)$ \\
\hline Median (range) & $36(18-75)$ & $43(18-70)$ & $39(18-75)$ \\
\hline \multicolumn{4}{|c|}{ Age at clinical onset (y) } \\
\hline Mean $( \pm S D)$ & $31( \pm 15)$ & N/A & $\mathrm{N} / \mathrm{A}$ \\
\hline Median (range) & $27(9-72)$ & N/A & N/A \\
\hline \multicolumn{4}{|l|}{ Mutation, n (\%) } \\
\hline m.11778G > A & $23(68 \%)$ & $28(76 \%)$ & $51(72 \%)$ \\
\hline $\mathrm{m} .3460 \mathrm{G}>\mathrm{A}$ & $6(18 \%)$ & $4(11 \%)$ & $10(14 \%)$ \\
\hline m.14484T $>C$ & $4(12 \%)$ & $3(8 \%)$ & $7(10 \%)$ \\
\hline Others ${ }^{\#}$ & $1(2 \%)$ & $2(5 \%)$ & $3(4 \%)$ \\
\hline
\end{tabular}

F, female; M, male; N/A, not applicable; SD, standard deviation; $y$, years; \# rare causal LHON mutation: $m .14487 \mathrm{~T}>\mathrm{C}$ (one participant) [33]; m.3958G >A (two participants). ${ }^{*} p<0.05$

Table 2 Information on smoking behaviour at study baseline

\begin{tabular}{|c|c|c|c|c|}
\hline & $\begin{array}{l}\text { LHON patients at baseline } \\
(n=34)\end{array}$ & $\begin{array}{l}\text { LHON patients before } \\
\text { onset }(n=34)\end{array}$ & $\begin{array}{l}\text { Asymptomatic LHON mutation } \\
\text { carriers }(n=37)\end{array}$ & $\begin{array}{l}\text { General } \\
\text { population }\end{array}$ \\
\hline \multicolumn{5}{|c|}{ Smoking status, n (\%) } \\
\hline Ever-smokers & $26(76 \%)$ & $23(68 \%)$ & $15(41 \%)$ & \\
\hline M & $22 / 28(79 \%)$ & 19/28 (68\%) & $5 / 7(71 \%)$ & \\
\hline F & $4 / 6(67 \%)$ & $4 / 6(67 \%)$ & $10 / 30(33 \%)$ & \\
\hline Current smokers & $16(42 \%)$ & $20(59 \%)$ & $12(32 \%)$ & $25 \%$ \\
\hline M & $14 / 28(50 \%)$ & $17 / 28(61 \%)$ & $5 / 7(71 \%)$ & $30 \%$ \\
\hline $\mathrm{F}$ & $2 / 6(33 \%)$ & $3 / 6(50 \%)$ & $7 / 30(23 \%)$ & $20 \%$ \\
\hline Ex-smokers & $10(29 \%)$ & $3(9 \%)$ & $3(8 \%)$ & \\
\hline M & $7 / 28(25 \%)$ & $2 / 28(7 \%)$ & $0 / 7(0 \%)$ & \\
\hline $\mathrm{F}$ & $3 / 6(50 \%)$ & $1 / 6(12 \%)$ & $3 / 30(10 \%)$ & \\
\hline Never smokers & $8(24 \%)$ & $11(32 \%)$ & $22(59 \%)$ & \\
\hline M & $6 / 28(21 \%)$ & $9 / 28(32 \%)$ & $2 / 7(29 \%)$ & \\
\hline F & $2 / 6(33 \%)$ & $2 / 6(33 \%)$ & $20 / 30(67 \%)$ & \\
\hline \multicolumn{5}{|c|}{ Pack-years, for ever-smokers } \\
\hline Mean $( \pm$ SD) & $14.1( \pm 13.0)$ & & $21.1( \pm 14.5)$ & \\
\hline Range & $0-42$ & & $0.1-102$ & \\
\hline \multicolumn{5}{|c|}{$\begin{array}{l}\text { FTND, for current smokers Nicotine } \\
\text { dependence: }\end{array}$} \\
\hline Very high & $2(15 \%)$ & & $0(0 \%)$ & \\
\hline High & $1(8 \%)$ & & $4(36 \%)$ & \\
\hline Moderate & $2(15 \%)$ & & $2(18 \%)$ & \\
\hline Low & $8(62 \%)$ & & $5(45 \%)$ & \\
\hline
\end{tabular}

FTND, Fagerström Test for Nicotine Dependence; SD, standard deviation 
Table 3 Information on self-reported alcohol consumption in our cohort of LHON mutation carriers, at study baseline

\begin{tabular}{|c|c|c|c|}
\hline & LHON patients $(\mathrm{n}=34)$ & $\begin{array}{l}\text { Asymptomatic LHON } \\
\text { mutation carriers } \\
(n=37)\end{array}$ & $\begin{array}{l}\text { General } \\
\text { population }\end{array}$ \\
\hline \multicolumn{4}{|l|}{ Self-reported excessive alcohol consumption before onset } \\
\hline (27/34 with data: $21 \mathrm{M} / 6 \mathrm{~F})$ & $8(30 \%)$ & N/A & $14 \%$ \\
\hline M & $7(33 \%)$ & N/A & M 16\% \\
\hline F & $1(17 \%)$ & N/A & F 13\% \\
\hline \multicolumn{4}{|l|}{ Self-reported excessive alcohol consumption at study baseline } \\
\hline (64/71 with data) & $7(26 \%)$ & $2(6 \%)$ & $14 \%$ \\
\hline M & $5(24 \%)$ & $0(0 \%)$ & M 16\% \\
\hline $\mathrm{F}$ & $2(33 \%)$ & $2(7 \%)$ & F 13\% \\
\hline \multicolumn{4}{|l|}{ AUDIT questionnaire, n (\%) } \\
\hline $\begin{array}{l}\text { Excessive alcohol consumption at study baseline (66/71 with data:32 Pat./34 } \\
\text { Asymp.) }\end{array}$ & $6(19 \%)$ & $4(12 \%)$ & \\
\hline \multicolumn{4}{|l|}{$\begin{array}{l}\text { Daily alcohol consumption at study baseline, g/day (68/71 with data: } 33 \text { Pat./35 } \\
\text { Asymp.) }\end{array}$} \\
\hline Mean $( \pm S D)$ & $12.8( \pm 15.8)$ & $6.4( \pm 11.1)$ & \\
\hline Range & $0-60$ & $0-54$ & \\
\hline \multicolumn{4}{|l|}{$\begin{array}{l}\text { Days of alcohol consumption at study baseline, } n \text { (\%) (68/71 with data: } 33 \text { Pat./35 } \\
\text { Asymp.) }\end{array}$} \\
\hline Daily & $3(9.1 \%)$ & $1(2.9 \%)$ & \\
\hline Weekly & $12(36.4 \%)$ & $10(28.6 \%)$ & \\
\hline Seldom & $11(33.3 \%)$ & $19(54.3 \%)$ & \\
\hline Non-drinker & $7(21.2 \%)$ & $5(14.3 \%)$ & \\
\hline
\end{tabular}

Asymp., asymptomatic mutation carriers; AUDIT, Alcohol Use Disorders Identification Test; Pat., patients; SD, standard deviation

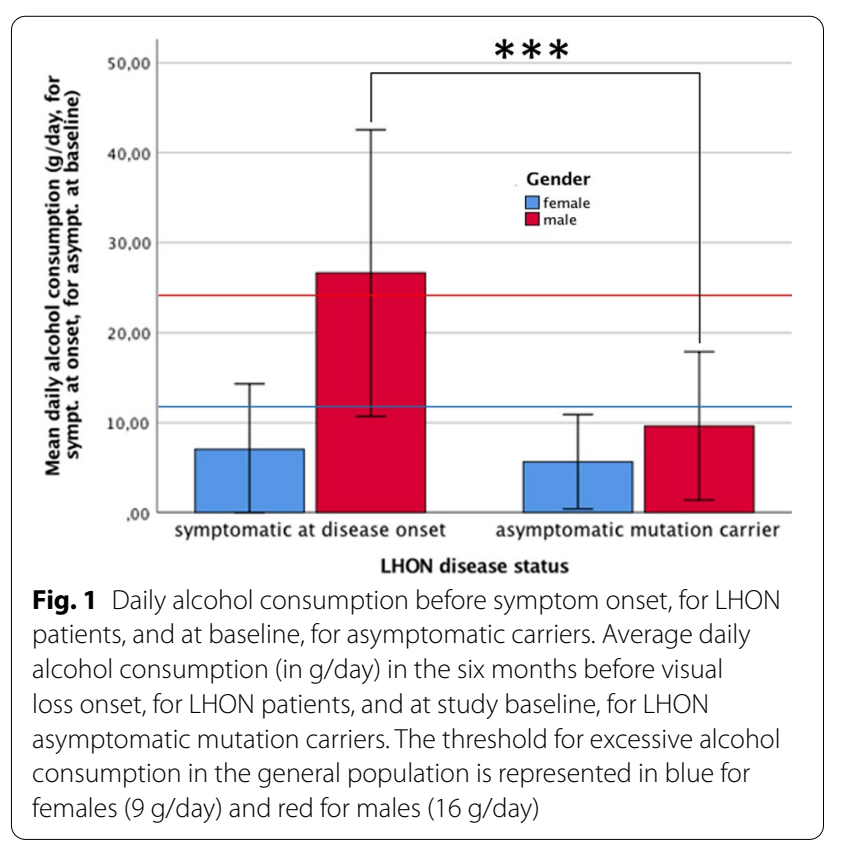

\section{Smoking behaviour}

The distribution of self-reported smoking behaviour for all participants is shown in Table 2. Data on smoking habits was available for LHON patients for the six months before onset of vision loss and also at study baseline, while for asymptomatic LHON mutation carriers smoking data was available only at study baseline, which here is equivalent to "before onset", because per definition there was no visual loss onset in the asymptomatic group.

The concentration of carbon monoxide in expired air correlated significantly with the self-reported daily cigarette consumption $(p<0.001)$.

In our cohort, the proportion of ever-smokers was higher among LHON patients at onset than in asymptomatic LHON mutation carriers (68\% vs. $41 \%$ ), and for each subgroup higher than in the general population $(25 \% ; p=0.02)$.

Before symptom onset, 59\% (20/34) of LHON patients and $42 \%(16 / 37)$ of asymptomatic LHON mutation carriers were current smokers, while $32 \%(11 / 34)$ of LHON patients at onset and 59\% (22/37) of asymptomatic LHON mutation carriers were never-smokers.

For male participants, 61\% (17/28) LHON patients before onset and 71\% (5/7) asymptomatic mutation carriers were current smokers, which is, for both groups, significantly more than the frequency of smokers in the 
general male population in Germany $\left(30 \% ; p=1 \times 10^{-5}\right.$ and $p=0.017$, respectively) [22] (Additional file 1 : Figure S1).

For female participants, 50\% (3/6) LHON patients before onset and $23 \%$ asymptomatic LHON mutation carriers were current smokers, not significantly different to the general female population (20\%) [22].

Additional file 2: Figure S2 shows a flowchart of smoking behaviour over time for the LHON patients, before disease onset and at study baseline. While very few LHON patients started smoking after symptom onset and five LHON patients continued their smoking behaviour despite visual loss onset, $60 \%(12 / 20)$ of LHON patients, who had smoked at disease onset, either stopped smoking or reduced smoking significantly after onset of visual loss. Interestingly, for about $45 \%$ of the LHON patients, who stopped smoking, some improvement of the visual acuity could be documented at last follow-up, versus $41 \%$ of the LHON patients, who continued smoking as before onset, but the numbers are not sufficiently large for robust conclusions (Figs. 1, 2).

The FTND score, which measures the degree of nicotine dependence, showed no statistically significant difference between LHON patients and asymptomatic LHON carriers (Table 2).

\section{Alcohol consumption}

Data on alcohol consumption in our cohort is summarized in Table 3, for both LHON patients and asymptomatic LHON mutations carriers, stratified by gender.

Thirty percent (8/27) LHON patients, who filled out the questionnaires on alcohol consumption, reported having had excessive alcohol consumption at disease onset [25]. Some LHON patients reported having reduced the alcohol consumption after disease onset, but the proportion of male LHON mutation carriers with excessive alcohol consumption (26\%) at study baseline was still significantly higher among LHON patients than in asymptomatic LHON mutation carriers $(p<0.001)$. None of the five male asymptomatic LHON mutation carriers reported excessive alcohol consumption. There is a higher proportion of male LHON patients (30\%) drinking alcohol excessively, compared to the male general population in Germany $(15.6 \%)$ [21, 25]. This was confirmed by the AUDIT data, where $19 \%$ of LHON patients presented excessive alcohol consumption even at study baseline, which was not the case for asymptomatic mutation carriers, as shown in Fig. 1.

\section{Depression data}

\section{Increased depression rates in female asymptomatic LHON} mutation carriers

For female asymptomatic LHON mutation carriers, $44 \%(12 / 27)$ had mild to moderate depression, which is higher than the prevalence rate of depression in the German female general population of $10.2 \%$ (28-30). No male asymptomatic LHON mutation carrier in this small subgroup $(n=7)$ reported depressive symptoms at study baseline (Table 4).

Female LHON mutation carriers at study baseline showed Beck Depression Inventory (BDI-I) depression scores, which were significantly higher for asymptomatic LHON carriers than for LHON patients $(p=0.02)$, as shown in Fig. 2.

For male LHON patients at study baseline, $8 \%(2 / 24)$ had mild to moderate depression, not significantly different to the $6 \%$ frequency of the male general population. In the small subgroup of female LHON patients $(n=6)$, none had criteria for depression at study baseline, but we could not collect the more relevant data on depression at LHON symptom onset in our study.

\section{Lower mental health-related QOL in female asymptomatic LHON mutation carriers}

Table 4 summarizes the health-related QOL data for our cohort of LHON patients and asymptomatic LHON mutation carriers, stratified by gender, as given by the SF-12v2. Mean PCS score was significantly lower for male LHON patients than the male general population $(p=0.015)$. PCS scores were also lower in the female LHON patients than in the female general population, but this was not statistically significant. For asymptomatic LHON mutation carriers, mean PCS scores were significantly higher for males $(p=0.006)$ and females $(p=0.016)$, compared to the gender-matched general population.

Remarkably, the MCS score, which is a proxy for mental health QOL, was lower for asymptomatic LHON mutation carriers than the general population $(p<0.001)$, and lower than for LHON patients at study baseline $(p=0.001)$ (Fig. 3). Interestingly, we found that female asymptomatic LHON mutation carriers score worse in mental QOL (MCS score) when compared to the female general population $(p<0.001)$. For the subgroup of female LHON patients, the sample is too small for robust comparisons. For males, there were no significant differences of the MCS scores, both for symptomatic and asymptomatic groups, compared to the general population. 


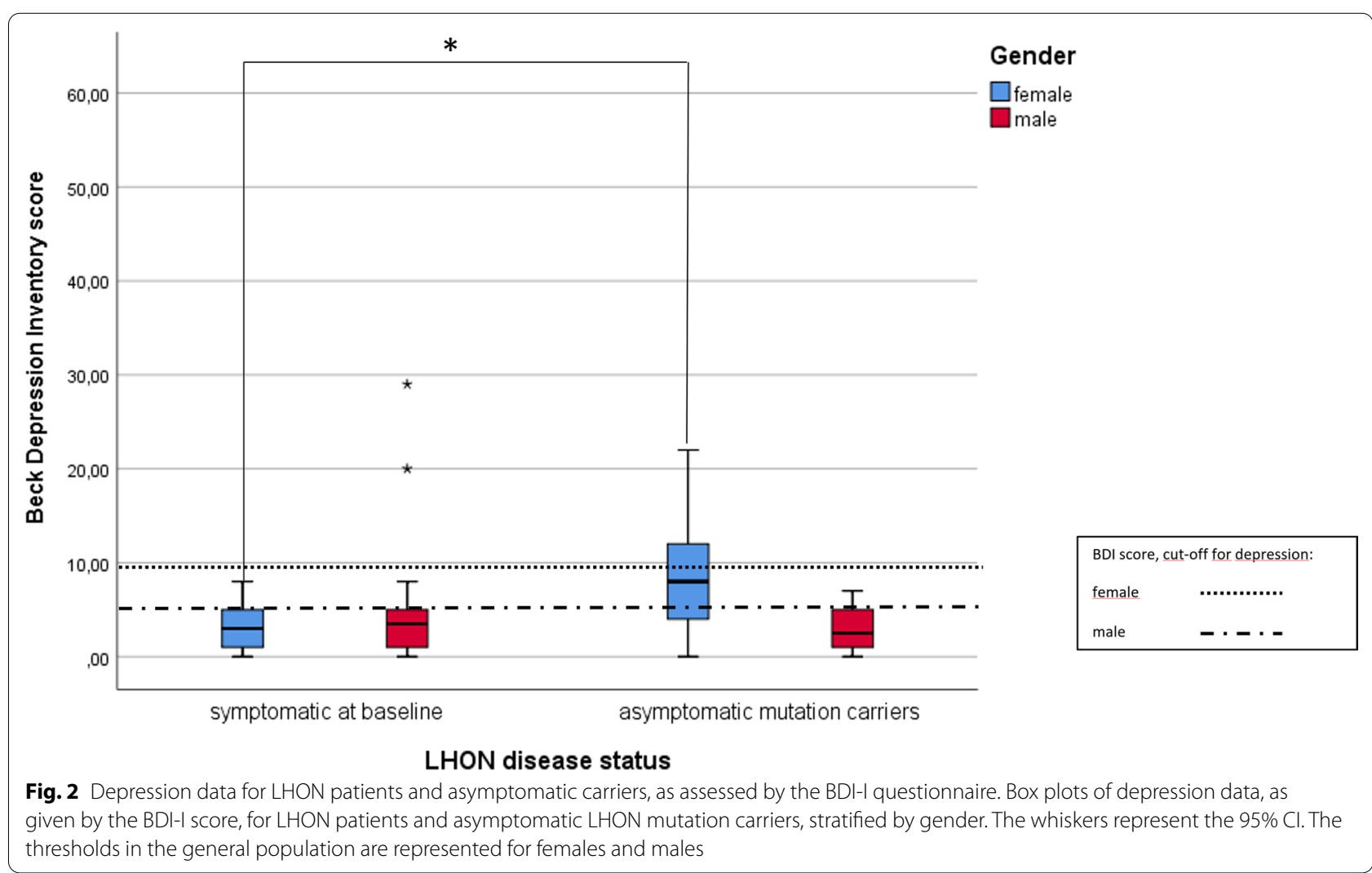

\section{Discussion}

LHON is the most frequent mitochondrial disorder and causes a high socio-economic burden. With the present study, we were able to show that LHON also causes a significant burden in mental health and quality of life, not only for LHON patients, but also for the asymptomatic at-risk relatives, who are carriers of a causal LHON mutation without showing symptoms.

Further, we could confirm the relevance of the previously described association between LHON and smoking as a potential risk factor for LHON mutation carriers [11], suggesting there is potential for risk reduction by prophylactic interventions such as lifestyle changes in this population. Both LHON patients and asymptomatic carriers smoke significantly more than the general population, with increased exposure to smoking described in large epidemiological studies to increase risk to develop disease. Smoking exposure for asymptomatic LHON mutation carriers may increase their risk of developing LHON, even if at the time of the study the disease may have not yet manifested.

Onset of visual loss in a previously asymptomatic LHON mutation carrier may serve as motivation to rethink smoking. Indeed, our data show that $60 \%$ of LHON patients, who were smokers at symptom onset, changed their smoking behaviour after experiencing onset of visual loss, with about a third stopping smoking altogether after disease onset. We found that $45 \%$ of the LHON patients, who stopped smoking, showed some improvement of visual acuity at last follow-up, compared to $41 \%$ of patients, who continued smoking despite onset of visual loss. However, numbers are relatively small. Also, the percentage of idebenone intake was different between the groups with clinical improvement (93\%) and without clinical improvement (65\%), and other factors may have confounded this analysis, which warrants analysis in a larger cohort.

Sharing the diagnosis of LHON with the patient and the relatives, in combination with effective communication of the relevance of the modifiable risk factors, presents a valuable opportunity to promote smoking cessation, with every subsequent visit in clinic providing a renewed chance to readdress this with the patient. At diagnosis, the LHON patient may be more motivated to quit smoking, as has been previously shown in cancer and chronic obstructive pulmonary disease [35, 36]. Remarkably, one-third of LHON patients in our study 

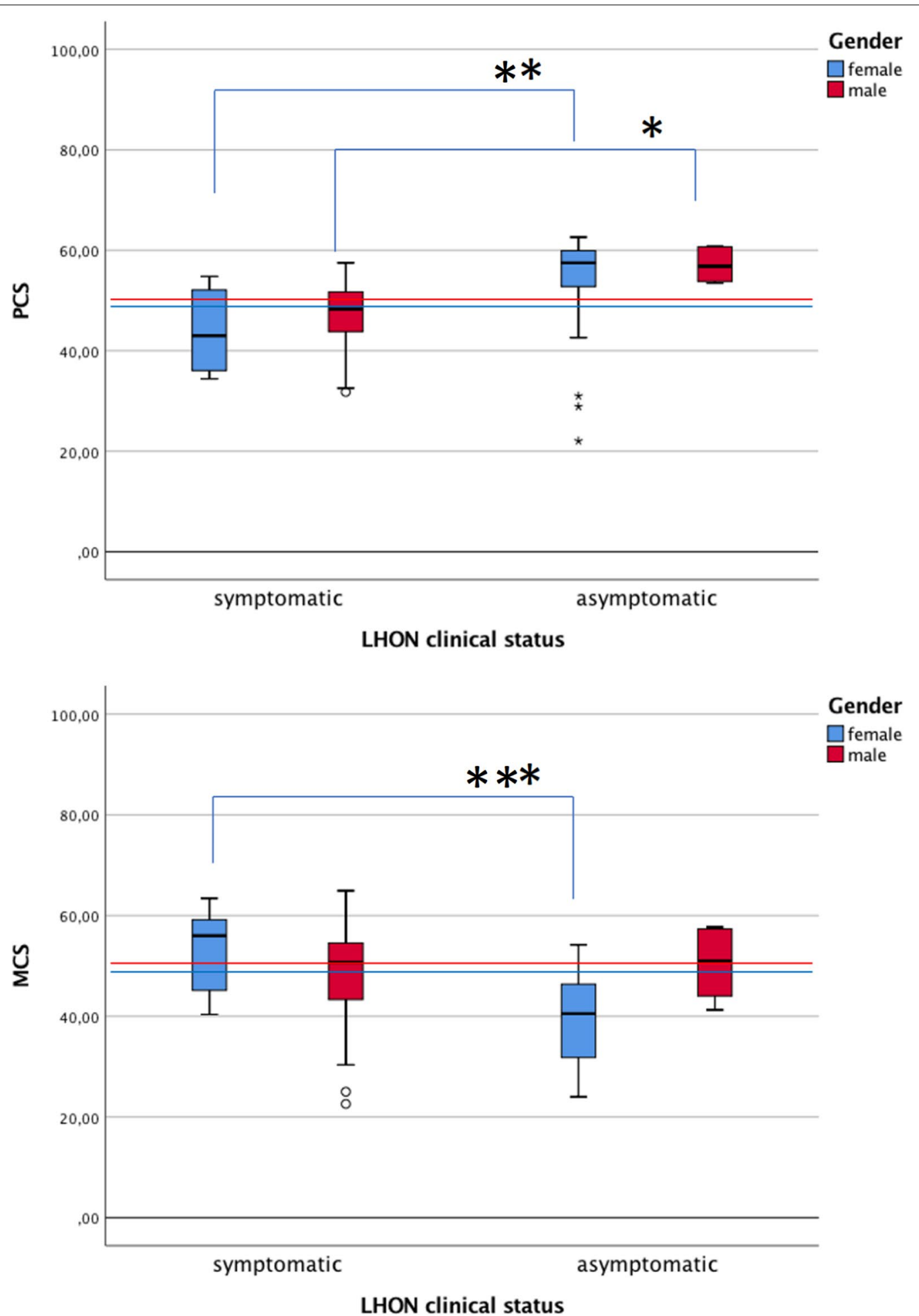

Fig. 3 Health-related quality of life for LHON patients and asymptomatic carriers, assessed by SF-12 v2 questionnaire. Box plots of the SF-12 V2 sub-scores: Physical Component Summary (PCS, above) and Mental Component Summary (MCS, below). The whiskers represent the $95 \% \mathrm{CI}$. The thresholds in the general population are represented in blue for females (MCS 48.4 and PCS 48.7) and red for males (MCS 50.4 and PCS 50.6) 
Table 4 Information on health-related quality of life (QOL) and prevalence of depressive symptoms at study baseline

\begin{tabular}{|c|c|c|c|}
\hline & LHON patients $(n=34)$ & $\begin{array}{l}\text { Asymptomatic LHON mutation carriers } \\
(\mathrm{n}=37)\end{array}$ & General population \\
\hline \multicolumn{4}{|c|}{ SF-12 v2 at study baseline } \\
\hline (68/71 with data) & $33 / 34$ & $35 / 37$ & \\
\hline MCS & $49.5 \pm 10.3$ & $41.4 \pm 9.5$ & N/A \\
\hline M & $48.7( \pm 10.6)$ & $50.38( \pm 7.0)$ & $50.4( \pm 9.9)$ \\
\hline $\mathrm{F}$ & $53.3( \pm 8.9)$ & $39.59( \pm 8.9)^{*}$ & $48.4( \pm 9.6)$ \\
\hline PCS & $46.7 \pm 6.9$ & $54.3 \pm 9.6$ & N/A \\
\hline M & $47.3( \pm 6.6)$ & $57.1( \pm 3.5)^{*}$ & $50.6( \pm 10.2)$ \\
\hline F & $43.9( \pm 8.4)$ & $53.7( \pm 10.4)$ & $48.7( \pm 9.6)$ \\
\hline \multicolumn{4}{|c|}{ BDI at study baseline } \\
\hline (63/71 with data) & $30 / 34$ & $33 / 37$ & \\
\hline \multicolumn{4}{|c|}{ Depressive symptoms: } \\
\hline Severe & 0 & 0 & $\begin{array}{l}\text { (Depression } \\
16-20 \% ; 10 \% \mathrm{~F} ; \\
6 \% \mathrm{M}) \text { ) }\end{array}$ \\
\hline Moderate & $2(7 \%)[2 \mathrm{M}]$ & $2(6 \%)[2 F]$ & \\
\hline Mild & 0 & $10(30 \%)[10 \mathrm{~F}]$ & \\
\hline Depression score & $4.5 \pm 6.0$ & $8.1 \pm 6.0^{*}$ & \\
\hline
\end{tabular}

BDI, Beck Depression Inventory; F, female; M, male; MCS, Mental Component Summary; N/A, not available; PCS, Physical Component Summary; SD, standard deviation; SF-12 v2, SF-12 version 2 questionnaire

${ }^{*} p<0.05$

will keep on smoking. Information on the health risks of smoking, but also advice and support on quitting addictive behaviours should be provided to LHON patients and asymptomatic mutation carriers at every clinic visit.

Concordant with the previously described association between heavy alcohol intake and increased risk of LHON [11], our study showed a statistically significant higher proportion of male LHON mutation carriers with excessive alcohol consumption at disease onset, compared to the male general population [21]. A proportion of LHON patients stopped or reduced their drinking habits after visual loss onset, but the prevalence of excessive alcohol consumption at study baseline was still more frequent than the prevalence of the general population.

Further, vitamin B12 deficiency was documented, either in the laboratory tests at baseline or in the previous medical history, in a significant proportion of the LHON patients in our cohort. A vitamin B12 deficiency may play a modulating role in the development of optic neuropathy, can be easily diagnosed and treated, and should therefore be routinely looked for in the population of LHON mutation carriers. This warrants further research in a larger cohort.

To our knowledge, ours is the first study looking at mental health and physical health-related QOL in LHON mutation carriers. It had previously been shown that visual deficits in LHON negatively impact the visual-related
QOL of LHON patients, as measured by the VF-14 scale $[18,37]$, but no study had previously systematically looked at the mental and physical health-related domains of QOL in the population of LHON mutation carriers. There are many dimensions to how the physical and mental QOL may be impacted in a LHON mutation carrier, given the risk of developing severe chronic visual impairment, or, for female carriers, also the risk their children may develop visual loss. In this study, we were able to show that female asymptomatic LHON mutation carriers score worse in mental QOL than the general population.

Further, the psychological impact of having a LHON mutation or becoming a patient with LHON had previously not been systematically studied. It has been described in the literature that men are, in general, more likely to develop or worsen addictive behaviours, such as alcoholism, whereas women are more likely to develop depressive symptoms, and that mental health and healthrelated behaviours, such as smoking and alcohol consumption, are closely linked [30,38]. In the subgroup of LHON mutation carriers we have observed this, with male LHON patients and male asymptomatic mutation carriers smoking significantly more than the general population. Also, our study highlights a high frequency of mental health issues in female asymptomatic LHON mutation carriers, with the mental well-being of female asymptomatic mutation carriers shown to be worse than 
the female general population. Further, we found that mild and moderate depression is more frequent in female asymptomatic mutation carriers. It can be expected that screening the mental health of this population may allow earlier identification and treatment of mental health issues. These may be compounded by the stress of having an affected relative, uncertainty given the risk of developing the disease, with consequent vision loss and disability, as well as uncertainty given the risk for their children. Our findings on QOL and on depression are consistent, for LHON patients and asymptomatic mutation carriers. Depressive symptoms are known to have a negative impact on health-related QOL [39]. Enhancing individual health-related QOL is an important therapeutic goal of every treatment and this is relevant when treating and counselling both LHON patients and asymptomatic LHON mutation carriers. In general, it has been described that people with psychiatric comorbidities, especially those with depressive symptoms, are more likely to be non-compliant to medical recommendations [40] and poor mental health is associated with healthrelated behaviours such as smoking, physical inactivity and poor nutrition [41]. In our study we did not look systematically at nutrition, physical activity and compliance to medical recommendations, for LHON mutation carriers.

Our study has some limitations. The data we collected on depression and QOL for the LHON patients reports to the study baseline, which occurred from 4 months to 36 years after onset of visual loss, which may mean that at least a proportion of LHON patients may already have readjusted [18], and, therefore, we may underestimate the real impact of depression and mental health issues in LHON patients. There is significant phenotypical heterogeneity in LHON and a large spectrum of disease severity and disability, with a proportion of patients having significant clinical improvement, others no clinical improvement whatsoever and severe visual loss, which may influence QOL and psychological impact of disease. LHON patients would be expected to have higher depression scores than what we found, if the questionnaires had been administered sooner after symptom onset, when they first start experiencing visual loss or shortly thereafter. After several months or years, some LHON patients may already had time to adapt to the new condition, therefore this analysis performed at study baseline may underestimate the frequency of depression in the LHON patients. Further, the data on alcohol consumption was self-reported, which may have yielded underreporting for some patients. Another limitation of our study is that published data on the general population was used for comparison, given the small size of our group of healthy controls, which did not allow robust statistical comparisons. Although our LHON cohort study has been set up longitudinally, the current study is based on the cross-sectional analysis of the baseline data of the subjects enrolled in the first two years. We cannot know at study baseline whether and when any asymptomatic mutation carrier will develop LHON disease in the future. Further, some recall bias can be expected for the retrospective self-reported data on smoking and alcohol consumption before clinical onset of LHON, making the information on exposure to environmental triggers before clinical onset, its duration and quantification, less accurate, even more so for LHON patients with longer disease duration.

\section{Conclusions}

Our study provides insights on lifestyle factors, psychiatric comorbidities, health-related QOL and psychological impact in both LHON patients and asymptomatic LHON mutation carriers. The high prevalence of smoking in LHON mutation carriers and excessive alcohol consumption in male LHON mutation carriers emphasizes the chance for effective prophylactic measures in the population of LHON mutation carriers, which may have a significant impact on future risk of disease manifestation and prognosis. We could show that female asymptomatic LHON mutation carriers are at particular risk for mental health issues. Promoting mental health in LHON mutation carriers may be expected to lead to more timely treatment and have a positive impact in mental health and QOL in LHON mutation carriers.

\section{Abbreviations}

ABV: Alcohol-by-volume; AUDIT: Alcohol use disorders identification test; BDI: Beck depression inventory; ETDRS: Early treatment diabetic retinopathy study; FTND: Fagerström test for nicotine dependence; LHON: Leber's hereditary optic neuropathy; MCS: Mental component summary; mtDNA: Mitochondrial DNA; PCS: Physical component summary; QOL: Quality of life.

\section{Supplementary Information}

The online version contains supplementary material available at https://doi. org/10.1186/s13023-021-01724-5.

Additional file 1: Figure S1 Flow chart describing smoking behaviour for the LHON patients in our cohort over time. Smoking behaviour before disease onset and at study baseline.

Additional file 2: Figure S2 Smoking habits for all participants in the study, LHON patients and asymptomatic LHON mutation carriers.

\section{Acknowledgements}

We would like to thank all the patients and their families for participating in this study. We thank Dr. Boriana Büchner and Oskars Mikazans (Friedrich-BaurInstitute, Department of Neurology, University Hospital, Ludwig-MaximiliansUniversity of Munich, Munich, Germany) for their contribution to study coordination and data management. 


\section{Authors' contributions}

$A R$ and $C B C$ contributed to the study design, data acquisition, analysis and manuscript preparation. VR, DS, CG and CP contributed to data acquisition and analysis. OP, TR and TK contributed to the study design, data acquisition, analysis and manuscript preparation. All authors read and approved the final manuscript.

\section{Funding}

Open Access funding enabled and organized by Projekt DEAL. This work was supported by grants from the German Bundesministerium für Bildung und Forschung (BMBF) funding the German network for mitochondrial disorders (mitoNET; 01GM1113A to T.K. for the mitoNET registry).

\section{Availability of data and materials}

The data analyzed during this study are available from the corresponding authors on reasonable request.

\section{Ethics approval and consent to participate}

This study was approved by the local Ethics committee of the Ludwig-Maximilians-University (LMU) of Munich (project number 278-13) and conformed to the principles of Good Clinical Practice.

\section{Consent for publication}

All participants and legal guardians (for participants under the age of 18 years) gave written informed consent or assent.

\section{Competing interests}

TK has been principal investigator or investigator in industry-sponsored trials funded by Santhera Pharmaceuticals and GenSight Biologics, served on scientific advisory board and received speaker honoraria and travel costs from Santhera Pharmaceuticals and GenSight Biologics. CBC received travel costs from Santhera Pharmaceuticals and GenSight Biologics. AR, CG, CP, DS, OP, TR and $V R$ report no disclosures.

\section{Author details}

${ }^{1}$ Department of Psychiatry and Psychotherapy, Ludwig-Maximilians University München, Nussbaumstr. 7, 80336 Munich, Germany. ${ }^{2}$ Department of Neurology, Friedrich-Baur Institute, Ludwig-Maximilians University München, Ziemssenstr. 1a, 80336 Munich, Germany. ${ }^{3}$ Department of Ophthalmology, Ludwig-Maximilians University München, 80336 Munich, Germany. ${ }^{4}$ Munich Cluster for Systems Neurology (SyNergy), Munich, Germany. ${ }^{5}$ German Center for Neurodegenerative Diseases (DZNE), Munich, Germany.

\section{Received: 12 June 2020 Accepted: 2 February 2021}

Published online: 11 March 2021

\section{References}

1. Man PY, Griffiths PG, Brown DT, Howell N, Turnbull DM, Chinnery PF. The epidemiology of Leber hereditary optic neuropathy in the North East of England. Am J Hum Genet. 2003;72(2):333-9.

2. Yu-Wai-Man P, Griffiths PG, Chinnery PF. Mitochondrial optic neuropathies - disease mechanisms and therapeutic strategies. Prog Retin Eye Res. 2011;30(2):81-114.

3. Barboni P, Savini G, Valentino ML, La Morgia C, Bellusci C, De Negri AM, et al. Leber's hereditary optic neuropathy with childhood onset. Invest Ophthalmol Vis Sci. 2006;47(12):5303-9.

4. Majander A, Bowman R, Poulton J, Antcliff RJ, Reddy MA, Michaelides M, et al. Childhood-onset Leber hereditary optic neuropathy. Br J Ophthalmol. 2017:101(11):1505-9.

5. Dimitriadis K, Leonhardt M, Yu-Wai-Man P, Kirkman MA, Korsten A, De Coo IF, et al. Leber's hereditary optic neuropathy with late disease onset: clinical and molecular characteristics of 20 patients. Orphanet J Rare Dis. 2014;9(1):1-5.

6. Wallace DC, Singh G, Lott MT, Hodge JA, Schurr TG, Lezza AM, et al. Mitochondrial DNA mutation associated with Leber's hereditary optic neuropathy. Science. 1988;242(4884):1427-30.

7. Howell N, Bindoff LA, McCullough DA, Kubacka I, Poulton J, Mackey $D$, et al. Leber hereditary optic neuropathy: identification of the same mitochondrial ND1 mutation in six pedigrees. Am J Hum Genet. 1991;49(5):939-50.
8. Johns DR, Neufeld MJ, Park RD. An ND-6 mitochondrial DNA mutation associated with Leber hereditary optic neuropathy. Biochem Biophys Res Commun. 1992:187(3):1551-7.

9. Brown MD, Trounce IA, Jun AS, Allen JC, Wallace DC. Functional analysis of lymphoblast and cybrid mitochondria containing the 3460, 11778, or 14484 Leber's hereditary optic neuropathy mitochondrial DNA mutation. J Biol Chem. 2000;275(51):39831-6.

10. Yu-Wai-Man P, Turnbull DM, Chinnery PF. Leber hereditary optic neuropathy. J Med Genet. 2002:39(3):162-9.

11. Kirkman MA, Yu-Wai-Man P, Korsten A, Leonhardt M, Dimitriadis K, De Coo IF, et al. Gene-environment interactions in Leber hereditary optic neuropathy. Brain. 2009;132(Pt 9):2317-26.

12. Hudson G, Keers S, Yu Wai Man P, Griffiths P, Huoponen K, Savontaus ML, et al. Identification of an X-chromosomal locus and haplotype modulating the phenotype of a mitochondrial DNA disorder. Am J Hum Genet. 2005;77(6):1086-91.

13. Johns DR, Smith KH, Miller NR, Sulewski ME, Bias WB. Identical twins who are discordant for Leber's hereditary optic neuropathy. Arch Ophthalmol. 1993;111(11):1491-4

14. Biousse V, Brown MD, Newman NJ, Allen JC, Rosenfeld J, Meola G, et al. De novo 14484 mitochondrial DNA mutation in monozygotic twins discordant for Leber's hereditary optic neuropathy. Neurology. 1997:49(4):1136-8

15. Pisano A, Preziuso C, lommarini L, Perli E, Grazioli P, Campese AF, et al. Targeting estrogen receptor $\beta$ as preventive therapeutic strategy for Leber's hereditary optic neuropathy. Hum Mol Genet. 2015;24(24):6921-31.

16. Smith P, Cooper J, Govan G, Harding A, Schapira A. Smoking and mitochondrial function: a model for environmental toxins. QJM. 1993:86(10):657-60

17. Tsao K, Aitken PA, Johns DR. Smoking as an aetiological factor in a pedigree with Leber's hereditary optic neuropathy. Br J Ophthalmol. 1999;83(5):577-81.

18. Kirkman MA, Korsten A, Leonhardt M, Dimitriadis K, De Coo IF, Klopstock T, et al. Quality of life in patients with leber hereditary optic neuropathy. Invest Ophthalmol Vis Sci. 2009;50(7):3112-5.

19. Bleich $S$, Havemann-Reinecke $U$, Kornhuber J. Fagerström-Test für Nikotinabhängigkeit: FTNA. Beltz-Test; 2002.

20. Heatherton TF, Kozlowski LT, Frecker RC, Fagerström K-O. The Fagerström test for nicotine dependence: a revision of the Fagerstrom Tolerance Questionnaire. Br J Addict. 1991:86(9):1119-27.

21. Pabst A, Kraus L, Matos EGd, Piontek D. Substanzkonsum und substanzbezogene Störungen in Deutschland im Jahr 2012. Sucht. 2013;59(6):321-31.

22. Krebsforschungszentrum D. Tabakatlas Deutschland 2015. Berlin: Pabst Science Publishers; 2015.

23. Saunders JB, Aasland OG, Babor TF, De la Fuente JR, Grant M. Development of the alcohol use disorders identification test (AUDIT): WHO collaborative project on early detection of persons with harmful alcohol consumption-II. Addiction. 1993:88(6):791-804.

24. Bühringer $G$, Augustin R, Bergmann E, Bloomfield K, Funk W, Junge B, et al. Alkoholkonsum und alkoholbezogene Störungen in Deutschland. Baden-Baden: Nomos; 2000

25. Burger M, Bronstrup A, Pietrzik K. Derivation of tolerable upper alcohol intake levels in Germany: a systematic review of risks and benefits of moderate alcohol consumption. Prev Med. 2004;39(1):111-27.

26. Hautzinger M, Worall H, Keller FBDI. Beck-Depressions-Inventar von AT Beck Dt. Bearbeitung. Göttingen: Hogrefe; 1995.

27. DGPPN B, KBV A, AkdÄ B, BApK D, DEGAM D, DGPs D. S3-Leitlinie/Nationale VersorgungsLeitlinie Unipolare Depression-Langfassung. DGPPN, ÄZQ AWMF, Berlin, Düsseldorf. 2009.

28. Ebmeier KP, Donaghey C, Steele JD. Recent developments and current controversies in depression. Lancet. 2006:367(9505):153-67.

29. Bijl RV, Ravelli A, van Zessen G. Prevalence of psychiatric disorder in the general population: results of The Netherlands Mental Health Survey and Incidence Study (NEMESIS). Soc Psychiatry Psychiatr Epidemiol. 1998;33(12):587-95.

30. Busch M, Maske U, Ryl L, Schlack R, Hapke U. Prävalenz von depressiver Symptomatik und diagnostizierter Depression bei Erwachsenen in Deutschland. Bundesgesundheitsblatt-Gesundheitsforschung-Gesundheitsschutz. 2013:56(5-6):733-9. 
31. Kosinski M, Ware JE, Turner-Bowker DM, Gandek B. User's manual for the SF-12v2 health survey: with a supplement documenting the SF-12 ${ }^{\circledR}$ health survey: QualityMetric incorporated; 2007.

32. Ellert U, Bellach BM. [The SF-36 in the Federal Health Survey--description of a current normal sample]. Gesundheitswesen. 1999;61 Spec No:S184-90.

33. Eckenweiler M, Catarino C, Gallenmueller C, Klopstock T, Lagrèze W, Korinthenberg R, et al. Mitochondrial DNA mutation 14487T> C manifesting as Leber's hereditary optic neuropathy. J Neurol. 2015:262(12):2776-9.

34. Ji Y, Liang M, Zhang J, Zhu L, Zhang Z, Fu R, et al. Mitochondrial ND1 Variants in 1281 Chinese Subjects With Leber's Hereditary Optic Neuropathy. Invest Ophthalmol Vis Sci. 2016;57(6):2377-89.

35. Westmaas JL, Newton CC, Stevens VL, Flanders WD, Gapstur SM, Jacobs EJ. Does a recent cancer diagnosis predict smoking cessation? An analysis from a large prospective US cohort. J Clin Oncol. 2015;33(15):1647-52.

36. Bednarek M, Gorecka D, Wielgomas J, Czajkowska-Malinowska M, Regula J, Mieszko-Filipczyk G, et al. Smokers with airway obstruction are more likely to quit smoking. Thorax. 2006;61(10):869-73.

37. Cui S, Jiang H, Peng J, Wang J, Zhang X. Evaluation of vision-related quality of life in Chinese patients with leber hereditary optic neuropathy and the G11778A mutation. J Neuroophthalmol. 2019;39(1):56-9.
38. Berger BD, Adesso VJ. Gender differences in using alcohol to cope with depression. Addict Behav. 1991;16(5):315-27.

39. Baumeister H, Balke K, Härter M. Psychiatric and somatic comorbidities are negatively associated with quality of life in physically ill patients. J Clin Epidemiol. 2005;58(11):1090-100.

40. DiMatteo MR, Lepper HS, Croghan TW. Depression is a risk factor for noncompliance with medical treatment: meta-analysis of the effects of anxiety and depression on patient adherence. Arch Intern Med. 2000;160(14):2101-7.

41. Prince M, Patel V, Saxena S, Maj M, Maselko J, Phillips MR, et al. No health without mental health. The lancet. 2007;370(9590):859-77.

\section{Publisher's Note}

Springer Nature remains neutral with regard to jurisdictional claims in published maps and institutional affiliations.
Ready to submit your research? Choose BMC and benefit from:

- fast, convenient online submission

- thorough peer review by experienced researchers in your field

- rapid publication on acceptance

- support for research data, including large and complex data types

- gold Open Access which fosters wider collaboration and increased citations

- maximum visibility for your research: over $100 \mathrm{M}$ website views per year

At $\mathrm{BMC}$, research is always in progress.

Learn more biomedcentral.com/submissions 